\title{
Effect of Resilience on Self-Perceived Stress and Experiences on Stress Symptoms A Surveillance Report
}

\author{
KWOK Sin Tung, WONG Wai Ning, Kris, LEE Tse Yan Alexander* \\ Faculty of Science and Technology, Technological and Higher Education Institute of Hong Kong, Tsing Yi, Hong Kong, China \\ *Corresponding Author: stellakwok@vtc.edu.hk
}

Copyright @ 2014 Horizon Research Publishing All rights reserved.

\begin{abstract}
The objectives of the study were to examine the level of perceived stress, emotional syndromes and quality of life among students and evaluate if personal resources is associated with students' stress level. All students were invited to participate. Socio-demographic characteristics and outcome measures including students' physical and psychological well-being and their personal resource/resilience (optimism, perceived control and self-esteem) were assessed via validated self-reporting questionnaires. Although only half of the student participants experienced some form of emotional symptoms, about $86.8 \%$ of the students still reported to have endured higher to much higher than average level of perceived stress. Significantly higher level of perceived stress was experienced by engineering students and those with lesser level of [poorer] resilience. Stressed students reported to have significantly poorer physical, psychological, social and environmental health. Results indicated that personal resilience affect the level of perceived stress experienced, and in turn affecting students' general well-being and hence, quality of life. In conclusion, a high level of stress and psychological symptoms associated with poor personal resilience in withstanding stress, as well as poor quality of life and general health among students were reported. Regular monitoring students' stress level and implementing appropriate intervention are recommended.
\end{abstract}

Keywords Perceived Stress, Stress Symptoms, Resilience, General Health, Quality of Life

\section{Introduction}

Psychological stress in adolescence, especially among those who are pursuing a professional degree, is one of the major factors that affect students' academic performance and satisfaction [1-4]. Besides academic demands, youngsters also encounter challenges in all aspects of their life as they are transiting into tertiary education and approaching adulthood [5-7]. These challenges can be positive and stimulating, bringing about motivation among students. However, it can also cause stress among students, affecting their general wellbeing in the long term. [5,8-10] Some unfortunate ones may even developmental issues such as depression and anxiety [1-2,10-12,14].

Youths with poorer personal resilience are less capable in handling and coping with stress [15-17], and good personal resilience is believed to help individual to recover from stressful events [17]. Kaplan [18] conceptualized resilience as a constellation of personal attitudes, attributes or dispositions, upon which one could draw to cope with difficult life situation. Taylor \& Brown [19] suggested self-esteem, perceived control and optimism as critical to one's success to adjust during stressful encounters. Major, et al. [20] and Wanberg [21] shared a similar view that self-esteem, perceived control, and optimism as a stable personality traits and attitudes combine to form a resilient personality. Some people are more resilient than others, and adapt well and recover quickly when facing difficulties. On the other hand, there are people who are less resilient, thus have much difficulty when facing challenges. They may continue to suffer from stress for a prolonged period [17]. Prolonged suffering from high-level stress is known to have caused anxiety and depression [16,24]. That ultimately affects the quality of life as a result of deterioration of physical and psychological well-being associated with stress [8-10,16,22,26-27]. Such deterioration of well-being may continue to intensify as students completing their education as well as transiting from education institution into workforce. Chronic suffering of stress, and associated physical and physiological symptoms could turn into a major public health issue $[16,27]$.

A number of suicide incidents associated with students from vocational education and training institutions as a result of stress were reported last year [28]. Such incidents have prompted educators to look at the severity of the problem and to implement appropriate measures that prevent such a devastating loss of life. At a newly established private post-secondary with vocational education oriented institution, the present study intended to investigate students' personal resilience as well as their perceived stress and associated psychological symptoms. The research team would also like to examine students' perceived general health and quality of life as well as their association with 
stress. It is proposed that students with poorer resilience would suffer from higher level of stress and stress associated symptoms which may affect their quality of life and general well-being. The present study would also like to examine if demographic characteristics have any impact on students' personal resilience and their stress level.

\section{Materials and Methods}

\subsection{Procedure}

All students (total of 257) in THEi were invited to fill in the survey. Prior to the survey distribution, a short briefing detailing the aims and procedures of the study including personal information and privacy were provided. Any clarification regarding to their participation and privacy issues were provided immediately by research personnel. After requesting for participation, an informed consent would then be distributed among student participants with the questionnaire. Socio-demographic characteristics and outcome measures including self-perceived physical and psychological well-being as well as personal resource/resilience (optimism, perceived control and self-esteem) were assessed via validated self-reporting survey. Upon completion of survey, students were asked to return the survey immediately to a collection box, folded or faced down to ensure privacy. A small incentive of a cash coupon would be provided as a token of appreciation for their participation.

\subsection{Target Population}

Not all students can run through the mainstream conventional education system where only the elites can succeed. In Hong Kong, the competition for a placement in government subsidized tertiary education institutions is intense. Students, even with a decent secondary school academic record, can still fail to gain entry into government-funded degree-awarding institution. For those who are unable to gain entry into any of these public institutions nor going back to secondary school for a second attempt, they often enter the workforce directly.

There are still students who would continue their study in private vocational education sectors. In 2012, the Vocational Training Council of Hong Kong launched its first batch of non-government subsidized vocational-oriented degree programmes to cater the continuous demands for post-secondary education. As an alternative to the public tertiary institution, the cost associated with this second chance education can be extravagant for many. Students in this education setting may experience much stress since the expectation on them to perform well academically is high. Together with other adolescents' stress, this group of students' stress level does indeed worthy of attention. As a new private post-secondary institution, THEi aims to provide quality professional education to all of its students while at the same time cater students' physical and psychological needs. It is worthwhile to assess the psychological profile of students so that effective intervention for stress management can be implemented to alleviate their stress and enhance their overall general and mental health. This can also help to improve their college life experience, enabling them to better perform in their study.

\subsection{Instruments}

\subsubsection{The World Health Organisation - Quality of Life Brief Version (WHOQOL-BREF)}

The World Health Organisation - Quality of Life (Brief Version) (WHOQOL-BREF) was used in the present study. It was derived from the original version of WHOQOL-100 which consists of 100 items to assess one's quality of life based on the six domains of physical health, psychological health, level of independence, environmental health, spirituality beliefs, and social relationship. The WHOQOL-BREF, as a self-administrated tool, consists of 26 items. The 26 items organized into four domains by merging physical health with level of independence and psychological health with spirituality belief while other domains unchanged. Two questions were added asking student participants to rate their quality of life and their general health. It has a good discriminant validity, content validity, internal consistency and test-retest reliability [30-31]. The Cronbach's $\alpha$ in the present study is 0.93 .

\subsubsection{Perceived Stress Scale (PSS-10)}

Perceived stress scale (PSS) is one of the most commonly used tools across different countries, cultures and population characteristics. It aims at accessing the degree to which situational changes in one's life are perceived as stressful [29]. A 10-items version was used in this study. It has a good internal consistency with alpha coefficient sitting at 0.85 [17]. The Cronbach's $\alpha$ however in the present study is 0.47 .

\subsubsection{Depression, Anxiety and Stress Scale -21 (DASS-21)}

Depression, Anxiety and Stress Scale -21 (DASS-21) is a self-report questionnaire consisting of 21 items aiming to measure depression (DASS-D), anxiety (DASS-A) and stress (DASS-S) which making up the three instrumental domains. It is widely used in both clinical $[13,25]$ and non-clinical sectors [32]. Goh [33] reported a mean alpha coefficient of 0.93 indicated a strong internal consistence. In the present study, consistent to previous studies, Cronbach's $\alpha$ is 0.94 .

\subsubsection{Mastery Scale (MS)}

Mastery Scale was used in the present study to assess one's personal perceived control. It taps the general feeling of personal control over life events [34]. The internal consistencies were using local samples has been reported as 0.77 and 0.79 [35-37]. In here, the internal consistency is $\alpha=0.63$. 


\subsubsection{Life Optimism Test - Revised (LOT-R)}

A revised version of LOT-R was used to measure one's level of optimism. It consists of 6 items using a 5-point Likert scale with a higher score representing higher level of optimism. The Chinese version of LOT-R (CLOT-R), adapted from Lai [38], was used in the present study. Its internal consistence ranged from 0.73 to 0.74 $[27,38]$.However, the study here only obtained a low internal consistency of $\alpha=0.22$.

\subsubsection{Rosenberg Self-Esteem Scale (Revised) (RSES-R)}

A 9-item revised Chinese version of the Rosenberg Self-Esteem Scale was used in the present study to measure students' self-esteem. Participants answered items on a 5 -point scales and final score is determined to examine the level of self-esteem. It can also be divided into two factors (positive and negative) for further analysis. It has a good internal reliability [27]. The Cronbach's $\alpha$ in the present study is 0.5 .

\subsection{Statistical Analysis}

Frequency analyses and other descriptive statistics were applied/used to explore the prevalence of stress experienced by students. Correlation and mean differences were also performed to explore the relationship among different variables with demographic and variables themselves acting as control measures. MS; LOT-R and RSES-R were grouped together to form a Resilience Scale (RS) with an aim to examine students' personal resources/resilience against stressful situation and everyday life [27]. All statistical analysis was performed using SPSS 20.

\section{Results}

The response rate of the survey was $90.66 \%(n=233)$. Majority were in the age group of $16-20$ years old $(n=200$; $94.3 \%)$ and only $5.2 \%(n=11)$ were 21 years old or older. Gender distributions were pretty even with slightly more than half of the participants being female ( $\mathrm{n}=101 ; 50.2 \%)$. Only $10 \%$ of participants were coming from single parent family and about $30 \%$ of them were sole child. Majority of students ( $\mathrm{n}=97,41.6 \%)$ were coming from Engineering courses, and Design $(\mathrm{n}=78 ; 33.5 \%)$ as well as Sport and Recreation $(n=58 ; 24.9 \%)$ made up the rest. Other characteristics such as age, household incoming, religious backgrounds were summarized in Table 1 .

Only $7.5 \%(n=16)$ participated students considered their quality of life to be poor and about $17.5 \%(n=37)$ of them dissatisfied with their general health. Strong significant correlations were found across all domains in WHOQOL-BREF. Physical health was strongly correlated with psychological health while both are also positively associated with environmental health (see Table 5).

Well about half of the students scored DASS-21 within the normal range in all scales: depression (60.2\%), anxiety
(52.6\%) and stress (67.8\%) (see Table 2). However, 86.8\% of them reported to have experienced a higher or a much higher than an average level of perceived stress (see Table 3). Significant strong correlations were found across DASS-21 subscales within the instrument ranging from 0.76 to 0.85 (see Table 5). Moderate correlation relationships were also found between PSS and DASS scores (ranged from $\mathrm{r}=0.408-0.464 ; \mathrm{p}<0.01$ ).

Table 1. Demographic Characteristics

\begin{tabular}{|c|c|c|}
\hline \multicolumn{2}{|c|}{ Demographic Characteristics } & \multirow{2}{*}{$\begin{array}{c}\text { Frequency } \\
200(94.8 \%)\end{array}$} \\
\hline Age & $16-20$ & \\
\hline Missing: 22 & $21-25$ & $11(5.2 \%)$ \\
\hline Gender & Males & $100(49.8 \%)$ \\
\hline Missing: 32 & Females & $101(50.2 \%)$ \\
\hline \multirow[t]{3}{*}{ Faculty } & $\begin{array}{l}\text { Science and } \\
\text { Technology }\end{array}$ & $97(41.6 \%)$ \\
\hline & $\begin{array}{c}\text { Sport and Recreational } \\
\text { Management }\end{array}$ & $58(24.9 \%)$ \\
\hline & Design & $78(33.5 \%)$ \\
\hline Family Status & Complete & $190(90.0 \%)$ \\
\hline Missing: 22 & Single Parent Family & $21(10.0 \%)$ \\
\hline \multirow[t]{4}{*}{ Household Income } & Below 10000 & 27 (13.5\%) \\
\hline & 10001-20000 & $40(35.0 \%)$ \\
\hline & 20001-30000 & $49(24.5 \%)$ \\
\hline & $30001-40000$ & $22(11.0 \%)$ \\
\hline Missing: 22 & 40001 or over & $32(16.0 \%)$ \\
\hline \multirow[t]{4}{*}{ Religion } & Catholic & $12(5.7 \%)$ \\
\hline & Buddhism & $11(5.3 \%)$ \\
\hline & Christian & $52(24.9 \%)$ \\
\hline & Taoism & $2(1.0 \%)$ \\
\hline Missing: 24 & No Religion & 132 (63.2\%) \\
\hline
\end{tabular}

Table 2. Frequency of students' self-perceived DASS-21 severity rating

\begin{tabular}{|c|c|c|c|}
\hline $\begin{array}{c}\text { Severity } \\
\text { Rating }\end{array}$ & $\begin{array}{c}\text { DASS-Stress } \\
N=211\end{array}$ & $\begin{array}{c}\text { DASS-Depression } \\
N=208\end{array}$ & $\begin{array}{c}\text { DASS-Anxiety } \\
N=209\end{array}$ \\
\hline Normal & $127(60.2 \%)$ & $116(55.0 \%)$ & $110(52.6 \%)$ \\
\hline Mild & $35(16.6 \%)$ & $34(16.1 \%)$ & $33(15.8 \%)$ \\
\hline Moderate & $31(14.7 \%)$ & $26(12.3 \%)$ & $26(12.4 \%)$ \\
\hline Severe & $11(5.2 \%)$ & $13(6.2 \%)$ & $13(6.2 \%)$ \\
\hline $\begin{array}{c}\text { Extremely } \\
\text { Severe }\end{array}$ & $7(3.3 \%)$ & $22(10.4 \%)$ & $27(12.9 \%)$ \\
\hline
\end{tabular}

Table 3. Student self-perceived PSS-10 severity rating

\begin{tabular}{|c|c|}
\hline Severity Rating & $\begin{array}{c}\text { PSS } \\
N=205\end{array}$ \\
\hline Much Lower than Average & $0(0.0 \%)$ \\
\hline Lower than Average & $6(2.9 \%)$ \\
\hline Average & $21(10.2 \%)$ \\
\hline Higher than Average & $105(51.2 \%)$ \\
\hline Much Higher than Average & $73(35.6 \%)$ \\
\hline
\end{tabular}

About half of the students were considered to have strong personal resilience (52.5\%). Within the subscale, optimism as measured by LOT-R; self-esteem by RSES-R and 
perceived control by Mastery Scale, were further analyzed. Over half of participants scored high in optimism, self-esteem and perceived control (see Table 4).

Correlations were found between WHOQOL-BREF, DASS-21, PSS-10, and Resilience Scale (see Table 5). Overall, DASS-21 subscales and PSS-10 were all significantly negative correlated against WHOQOL-BREF subscales. Strong significant correlations were found among different domains of WHOQOL-BREF survey (ranged from $\mathrm{r}=0.517-0.714, \quad \mathrm{p}<0.01$ ) (see Table 5). Correlation relationship was large between self-esteem and optimism $(\mathrm{r}=0.565, \mathrm{p}<0.01)$ as well as between self-esteem and perceived control $(r=0.702, p<0.000)$ (see Table 5). For the combined score of resilience scale (result not shown), resilience score was significantly correlated to PSS-10 $(\mathrm{r}=-0.311, \mathrm{p}<0.01)$ and across all DASS-21 subscales [DASS-S ( $\mathrm{r}=-0.337, \mathrm{p}<0.01)$; DASS-D $(\mathrm{r}=-0.383, \mathrm{p}<0.01)$ DASS-A ( $\mathrm{r}=-0.348, \mathrm{p}<0.01)]$.

It was found that females scored significantly higher in DASS-Stress [t(196) $=1.953, \mathrm{p}=0.05]$ and DASS-Anxiety $[\mathrm{t}(196)=2.565, \mathrm{p}<0.05]$ with poorer self-perceived social relationship $[\mathrm{t}(199)=2.767, \mathrm{p}<0.01]$ than males (result not shown). On average, students coming from single parent family had a significantly lower self-esteem [t(154)=2.31, $\mathrm{p}<0.05$ ] and total resilience [t(154) $=1.975$, $\mathrm{p}<0.05$ ]. Religion only had a positive significant impact on environmental health of students $[\mathrm{t}(207)=2.311, \mathrm{p}<0.05]$. The effect size for each of all the personal characteristics however was between small and moderate ( $\eta 2$ ranged from 0.02 to 0.03 ) despite of its significance. Faculty where students belong played a significant effect across various domains of WHOQOL-BREF and Resilience Scale as well as PSS-10 scores (see Table 4). Upon a closer examination, most of these significant relationships however existed either between Engineering students and Sport \& Recreational Management students or Engineering students and Design students. Household income, siblings and students' employment status had no impact at all.

In students' self-perceived general health in WHOQOL-BREF, students who considered themselves to have poorer general health tended to exhibit significantly higher score in DASS-21 and PSS-10 as well as having a significantly lower resilience score. Likewise, students dissatisfied with their quality of life also tended to score significantly higher in DASS-21, PSS-10 and Resilience Scale (see Table 6).

Table 4. Mean score comparison of WHOQOL, DASS and PSS according to Faculty

\begin{tabular}{|c|c|c|c|c|}
\hline & $\begin{array}{c}\text { Sport Recreation } \\
\text { Management }\end{array}$ & Design & Engineering & $F$ \\
\hline QOL Physical Health & $15.03(2.03)^{*}$ & $13.95(2.78)$ & $13.88(2.52)^{*}$ & $\mathrm{~F}(2,209)=4.249, \mathrm{p}=0.016$ \\
\hline QOL Psychological & $14.00(1.76)^{*}$ & $13.20(2.56)$ & $12.87(2.48)^{*}$ & $\mathrm{~F}(2,209)=4.186, \mathrm{p}=0.017$ \\
\hline QOL SocialRelationship & $14.41(2.59)^{*}$ & $13.89(2.36)^{+}$ & $12.80(2.92)^{*^{+}}$ & $\mathrm{F}(2,209)=7.123, \mathrm{p}=0.001$ \\
\hline QOL Environment & $14.23(1.88)^{*}$ & $13.28(2.482)$ & $13.26(2.671)^{*}$ & $\mathrm{~F}(2,209)=3.244, \mathrm{p}=0.041$ \\
\hline DASS-Stress & $5.47(3.78)$ & $6.72(4.25)$ & $5.90(3.91)$ & $\mathrm{F}(2,205)=1.526, \mathrm{p}=0.220$ \\
\hline DASS-Depression & $3.47(3.74)$ & $4.74(4.25)$ & $4.43(3.82)$ & $\mathrm{F}(2,208)=1.698, \mathrm{p}=0.186$ \\
\hline DASS-Anxiety & $3.67(3.85)$ & $5.21(4.18)$ & $4.32(3.94)$ & $\mathrm{F}(2,206)=2.254, \mathrm{p}=0.108$ \\
\hline PSS-10 & $19.15(3.30)$ & $18.42(3.65)^{+}$ & $20.01(3.76)^{+}$ & $\mathrm{F}(2,202)=3.550, \mathrm{p}=0.031$ \\
\hline Optimistism & $19.94(2.67)^{*}$ & $18.12(5.22)$ & $16.8(3.77)^{*}$ & $\mathrm{~F}(2,175)=7.383, \mathrm{p}=0.001$ \\
\hline Self-Esteem & $33.54(5.14)^{*}$ & $29.99(5.96)^{+}$ & $29.33(5.88)^{*}$ & $\mathrm{~F}(2,179)=5.356, \mathrm{p}=0.000$ \\
\hline Perceived Control & $23.12(3.51)$ & $22.20(3.71)$ & $21.70(3.31)$ & $\mathrm{F}(2,177)=2.190, \mathrm{p}=0.115$ \\
\hline Resilience & $76.60(9.97)^{*}$ & $70.15(12.27)^{+}$ & $67.74(11.25)^{*^{+}}$ & $\mathrm{F}(2,173)=8.479, \mathrm{p}=0.000$ \\
\hline
\end{tabular}


Table 5. Correlation among Dimensions of WHOQOL-BREF; DASS-21 and PSS-10

\begin{tabular}{|c|c|c|c|c|c|c|c|c|c|c|}
\hline & $\begin{array}{c}\text { QOL } \\
\text { Psychological }\end{array}$ & $\begin{array}{c}\text { QOL Social } \\
\text { Relationship }\end{array}$ & $\begin{array}{c}\text { QOL } \\
\text { Environment }\end{array}$ & $\begin{array}{c}\text { DASS } \\
\text { Stress }\end{array}$ & $\begin{array}{c}\text { DASS } \\
\text { Depression }\end{array}$ & $\begin{array}{c}\text { DASS } \\
\text { Anxiety }\end{array}$ & PSS & Optimism & Self-Esteem & $\begin{array}{c}\text { Perceived } \\
\text { Control }\end{array}$ \\
\hline QOL Physical Health & $0.708^{* *}$ & $0.514^{* *}$ & $0.714^{* *}$ & $-0.449^{* *}$ & $-0.489^{* *}$ & $-0.437^{* *}$ & $-0.432^{* *}$ & $0.298^{* *}$ & $0.435^{* *}$ & $0.380^{* *}$ \\
\hline QOL Psychological & & $0.600^{* *}$ & $0.709^{* *}$ & $-0.404^{* *}$ & $-0.470^{* *}$ & $-0.384^{* *}$ & $-0.477^{* *}$ & $0.392^{* *}$ & $0.482^{* *}$ & $0.376^{* *}$ \\
\hline $\begin{array}{c}\text { QOL Social } \\
\text { Relationship }\end{array}$ & & & $0.517^{* *}$ & $-0.208^{* *}$ & $-0.263^{* *}$ & $-0.158^{*}$ & $-0.291^{* *}$ & $0.377^{* *}$ & $0.348^{* *}$ & $0.242^{* *}$ \\
\hline QOL Environment & & & & $-0.281^{* *}$ & $-0.325^{* *}$ & $-0.249^{* *}$ & $-0.281^{* *}$ & $0.286^{* *}$ & $0.320^{* *}$ & $0.354^{* *}$ \\
\hline DASS-Stress & & & & & $0.763^{* *}$ & $0.849^{* *}$ & $0.464^{* *}$ & $-0.219^{* *}$ & $-0.341^{* *}$ & $-0.255^{* *}$ \\
\hline DASS-Depression & & & & & & $0.820^{* *}$ & $0.440^{* *}$ & $-0.204^{*}$ & $-0.401^{* *}$ & $-0.348^{* *}$ \\
\hline DASS-Anxiety & & & & & & & $0.408^{* *}$ & $-0.195^{*}$ & $-0.362^{* *}$ & $-0.318^{* *}$ \\
\hline PSS-10 & & & & & & & & $-0.229^{* *}$ & $-0.267^{* *}$ & $-0.285^{* *}$ \\
\hline Total Optimism & & & & & & & & & $0.565^{* *}$ & $0.424^{* *}$ \\
\hline Total Self-Esteem & & & & & & & & & & $0.702^{* *}$ \\
\hline
\end{tabular}

** Correlation is significant at the 0.01 level

* Correlation is significant at the 0.05 level

Table 6. Mean Score of WHOQOL, DASS and PSS and their relationship with WHOQOL Self-Rated Quality of Life

\begin{tabular}{|c|c|c|c|c|}
\hline General Health & Poor & Neutral & Good & $\mathrm{F}$ \\
\hline Quality of Life & Dissatisfied & Neutral & Satisfied & \\
\hline \multirow[t]{2}{*}{ QOL Physical Health } & $11.71(3.870)^{*}$ & $13.63(2.345)^{*}$ & $14.98(2.048)^{*}$ & $F(2,209)=17.752, p=0.000$ \\
\hline & $12.02(3.007)^{*}$ & $13.36(1.933)^{*}$ & $15.53(1.814)^{*}$ & $F(2,209)=46.685, p=0.000$ \\
\hline \multirow[t]{2}{*}{ QOL Psychological } & $10.62(2.593)^{*}$ & $12.22(2.048)^{*}$ & $14.39(1.867)^{*}$ & $F(2,209)=43.132, p=0.000$ \\
\hline & $11.08(2.558)^{*}$ & $12.64(1.813)^{*}$ & $14.44(1.892)^{*}$ & $F(2,209)=43.706, p=0.000$ \\
\hline \multirow[t]{2}{*}{ QOL SocialRelationship } & $11.42(3.372)^{*}$ & $12.65(2.754)+$ & $14.50(2.259)^{*+}$ & $F(2,209)=18.531, p=0.000$ \\
\hline & $12.27(2.921)^{*}$ & $12.85(2.708)+$ & $14.45(2.423)^{*+}$ & $F(2,209)=13.284, p=0.000$ \\
\hline \multirow[t]{2}{*}{ QOL Environment } & $9.69(3.219)^{*}$ & $12.85(2.043)^{*}$ & $14.55(1.838)^{*}$ & $F(2,209)=46.912, p=0.000$ \\
\hline & $11.51(3.010)^{*}$ & $12.78(1.924)^{*}$ & $14.72(1.826)^{*}$ & $F(2,209)=38.316, p=0.000$ \\
\hline \multirow[t]{2}{*}{ DASS-Stress } & $8.19(4.608)^{*}$ & $6.56(3.897)$ & $5.33(3.824)^{*}$ & $F(2,205)=4.960, p=0.008$ \\
\hline & $8.62(4.505)^{*}$ & $6.63(3.605)^{*}$ & $4.71(3.486)^{*}$ & $F(2,205)=16.357, p=0.000$ \\
\hline \multirow[t]{2}{*}{ DASS-Depression } & $6.94(5.260)^{*}$ & $5.01(3.803)+$ & $3.36(3.570)^{*+}$ & $F(2,208)=8.734, p=0.000$ \\
\hline & $6.70(5.333)^{*}$ & $4.63(3.438)^{*}$ & $3.18(3.230)^{*}$ & $F(2,208)=12.647, p=0.000$ \\
\hline \multirow[t]{2}{*}{ DASS-Anxiety } & $5.69(4.207)$ & $5.05(4.107)$ & 3.77 (3.828) & $F(2,206)=3.339, p=0.037$ \\
\hline & $7.14(5.133)^{*}$ & $5.03(3.656)^{*}$ & $3.08(3.170)^{*}$ & $F(2,206)=17.382, p=0.000$ \\
\hline \multirow[t]{2}{*}{ PSS-10 } & $22.00(4.163) *$ & $20.21(3.117)+$ & $18.28(3.600) *_{+}$ & $F(2,202)=12.385, p=0.000$ \\
\hline & $21.21(4.121)^{*}$ & $20.33(3.037)+$ & $18.04(3.424)^{*+}$ & $F(2,202)=15.280, p=0.000$ \\
\hline \multirow[t]{2}{*}{ Optimism } & $16.38(4.719)$ & $17.84(4.026)^{+}$ & $19.26(3.135)^{+}$ & $F(2,155)=4.416, p=0.014$ \\
\hline & $17.12(3.822)^{*}$ & $17.98(3.092)$ & $19.33(3.768)^{*}$ & $F(2,155)=4.622, p=0.011$ \\
\hline \multirow[t]{2}{*}{ Self-Esteem } & $28.63(8.417)$ & $29.37(6.634)^{+}$ & $31.98(5.190)+$ & $F(2,158)=4.098, p=0.018$ \\
\hline & $27.84(7.284)^{*}$ & $29.50(4.519)+$ & $32.43(6.028)^{*+}$ & $F(2,158)=7.836, p=0.001$ \\
\hline \multirow[t]{2}{*}{ Perceived Control } & 21.38 (4.719) & $21.36(3.790)+$ & $23.08(3.181)+$ & $F(2,158)=4.673, p=0.011$ \\
\hline & $20.88(4.024)^{*}$ & $21.73(3.396)$ & $23.11(3.398)^{*}$ & $\mathrm{~F}(2,156)=4.9 .9, \mathrm{p}=0.008$ \\
\hline \multirow[t]{2}{*}{ Resilience } & $66.38(16.724)$ & $68.47(12.940)^{+}$ & $74.41(9.586)+$ & $F(2,158)=5.786, p=0.004$ \\
\hline & $65.84(13.256)^{*}$ & $69.10(9.021)+$ & $74.99(11.693)^{*+}$ & $F(2,153)=8.262, p=0.000$ \\
\hline
\end{tabular}




\section{Discussion}

Similar to previous studies both locally [24] and abroad $[1,6-7,39]$ only very few relationships existed between demographic characteristics and stress/stress related symptoms. Such relationships were often gender oriented with female typically experiencing more stress and anxiety as reflected in the present and past studies $[1,24,40]$. However, as with many previous studies, our findings only had a small to moderate effect size rendering interpretation questionable. It is reasonable to conclude that stress suffered and the subsequent stress associated symptoms experienced by students in the present study were indeed quite universal and not necessary accounted by personal demographic characteristics.

Notwithstanding, students of different faculties seemed to display different level of resilience and thus experienced different level of stress and stress symptoms, contributing to significant differences on their general well-being. Sport and recreational management students seemed to flair better in almost all aspects of life from better health and social/environmental interaction to lower stress associated symptoms, although not all differences were significant. They also possessed with significantly better personal resilience (more optimistic, better self-esteem and better perceived control). However, their perceived stress score was sitting in between engineering students and design students. Result indicated that even though students from sport and recreational management may have higher perceived stress than that of design students, they generally reported to have experienced less stress symptoms and better in physical health. And that may in part be due to their course structure as being more activities oriented physical education $[4,46]$. .

Physical leisure activities and recreational facilities availability has been indicated as one of the key factors in combating stress [4,41-42], raising resilience [41], providing positive college experience [43] as well as improving health and psychological well-being [5]. As a new post-secondary institution, communal recreational facilities are very limited within the campus. Therefore, students from sport and recreational management have a distinct advantage when come to physical leisure activities when comparing to engineering and design students since they have their own physical exercise facilities for their study. However, such a disadvantage may diminish after more communal recreational facilities are built.

Alternative explanation of the findings may be the result on the more challenging coursework among engineering students comparing to sport and recreational management students and design students. Many past studies have reviewed that stress is particularly common among students of medical [7,11,43]; engineering [4] and nursing [44] faculties because their courses' syllabus contents are more challenging in order for students to attain professional status within a short period of time. Though the past studies have investigated the level of stress experienced by students from engineering and sport-oriented course, little has done to study the perceived stress level experienced by design students. The findings in the present study found that design students seemed to experience the lowest level of stress but with good many reported to have suffered stress symptoms. Since many findings were insignificant, rendering interpretation of result inconclusive. Future study may need to invest more effort into exploring this area.

Students in the present study reported to have experienced higher to much higher than average level of perceived stress. The level of self-reported perceived stress reported was a lot higher than past studies [7,11]. It has been reported that students who were better off financially generally suffered less stress than those with financial hardship $[11,23]$. The target population was full-fee paying students who have failed to gain entry into a conventional public tertiary institution where government subsidized a major portion of the tuition fees. As a result, students in present study may be placed under considerable demands to perform better against the financial burden associated with their education. In addition, the survey was taken after the semester examination. The reality of academic achievement in meeting expectation may further intensify the stress they were experiencing $[2,15,23]$. Therefore, it was not surprised to find that good majority of students reported to have experienced a high level of stress. Let along stress itself is a hindering factor against academic performance [8]. Future study may want to expand the target population to compare full-fee paying against partial-fee paying students as well as to examine the relationship among GPA scores, academic achievement expectation and students' perceived stress.

Sing \& Wong [9] and Chung \& Cheung [8] established that high level of stress is a predominant risk factor affecting sleep and subsequent psychosocial and cognitive dysfunction among students in Hong Kong. Stewart, et al. [10] also found that Hong Kong adolescents generally exhibit somatic and cognitive symptoms when distressed. Despite suffering from a high level of perceived stress, more than half of the students in present study reported their stress related symptoms within the normal range. About 23.2\%, $31.5 \%$ and $28.9 \%$ students were suffering from moderate to extreme severity symptoms associated with stress, anxiety and depression which were consistent to previous studies $[1,24]$. This finding also reflected in the students' responses in WHOQOL-BREF where only $17.5 \%$ of the students claimed to be dissatisfied with their general health. It may indicate that students who were suffering from high level of stress were unaware of the associated symptoms. Stewart, et al. [10] argued that culture played a considerable role on the expression of distress symptoms. However, Ng \& Hurry [16] warned that an inability to identify stress and poor awareness of distress feeling may cause inability to cope and express negative emotion, exposing individuals to prolonged stress. As a result, their educational attainment and quality of life as well as family life and institutional life may be disrupted, which can manifest into a major public health concern [24]. Stewart-Brown, et al. [45] argued that high levels of stress 
and anxiety among tertiary students are normal and inevitable but Wong, et al. [24] suggested that given an early detection and implementing appropriate interventions are necessary to enhance students' psychological wellbeing, thereby reduce the morbidity and possible impairment among them in the future. Therefore, in responding to this finding, regular monitoring of students' stress and subsequent impacts on their physical and mental health is recommended.

Persons with lower resilience tended to equip with poorer coping skills [17]. Poor coping skills were associated with high level of stress [15-16]. As a result, it may ultimately affect one's quality of life and general health [8-9,27,29]. Findings in the present study supported the hypothesis and found that individual with lower personal resilience tended to suffer from significantly higher level of stress and associated symptoms, leading to lower quality of life and general health. Steinhardt \&Dolbier [17] found that improving individual resilience can significantly improve coping skills. Khalsa, et al. [41] also found that improving resilience help to reduce fatigue and improve anger control among students. The present research team is therefore designed to further the present study through the development of resilience training workshop to help improve students' coping skills, thereby alleviating their stress while promoting better mental health and college experience..

\section{Study Limitation, Justification and Recommendation}

Compared to many past studies, the present study was carried out in a newly established post-secondary institution where student numbers were limited, hence a small sample size. Results acquired can only be seen as preliminary nature. Cautious must be taken when interpreting data to avoid bias and misleading. Nonetheless, research team still believed that the results gathered in the present study worthy of attention considering the high number of students reported to have endured higher to much higher than average amount of perceived stress. Further study should try to collaborate with other post-secondary and tertiary institutions in acquiring a greater sample size for better analysis and more accurate result in reflecting the current situation experienced by target students. Source of stress, specific general health problems (such as insomnia), days of sick leave and GPA scores may help to further clarify the understanding of the stress issues and its impacts facing our students.

Furthermore, not all students complied with experimental protocol. In this case, answering the survey fully and truthfully. There were numerous complaints over the length of the survey, thereby many students were reluctant to participate. Though we provided incentive for students who completed the survey, many did not complete the survey which explained the relatively high number of missing data. It is the only limitation that cannot be controlled for when coming on self-reporting study. It is a risk to which all studies of this kind would have to come across. Educating students on the importance of research in tertiary education may help soften students' negative attitude toward survey study, hence help to boost the response rate.

\section{Conclusion}

The present study found that students with better resilience generally exhibit lower stress and related symptoms while with better health and hence quality of life. Despite a high level of stress experienced by students, they were generally unaware of the associated symptoms. Regularly monitoring students' stress level and implementing appropriate intervention to help students better cope with stress were recommended. Resilience training is to be implemented by the research team.

Engineering students were suffering the highest level of stress while sport and recreational management flair the best in almost all aspects examined in the present study, although some of the latter are experiencing high level of perceived stress. The present study proposed that higher level physical activities centered in the curriculum of sport and recreational management course may be a factor of this finding but further in depth investigation on design students may be needed to clarify result. Findings from design students were inconclusive and the present study proposed for further study to be conducted in exploring academic stress facing students who are studying design courses. Further studies in developing a theoretical framework and exploration of essential generic stressors included academic stress are necessary. Effective intervention could also be developed to help students manage stress and perform better academically and socially.

\section{Acknowledgements}

This project was funded by THEi seed grant under project no. 1213102. The support of THEi is acknowledged.

\section{REFERENCES}

[1] N. Bayram, N. Bilgel. The prevalence and socio-demographic correlations of depression, anxiety and stress among a group of university students. Social Psychiatry and Psychiatric Epidemiology. Vol.43, 667-672.

[2] M. S. DeBeard, G. I. Spielmans, D. L. Julka. Predictors of academic achievement and retention among college freshmen: a longitudinal study. College Student Journal. Vol.38, No.1, 66-80.

[3] P. P. Nandamuri, G. Ch. Sources of academic stress - a study on management students. Journal of Management \& Science. Vol.1, No.2, 31-42.

[4] S. Kumar, J. P. Bhukar. Stress level and coping strategies of 
college students. Journal of Physical Education and Sport Management. Vol.4, No.1, 5-11

[5] S. R. Bray, M. Y. W. Kwan. Physical Activity is associated with better health and psychological well-being during transition to University Life. Journal of American College Health. Vol.55, No.2, 77-82.

[6] J. Firth. Levels and sources of stress in medical students. British Medical Journal. Vol.292, 1177-1180.

[7] M. Shah, S. Sasan, S. Malik, C. T. Sreeramareddy. Perceived stress, sources and severity of stress among medical undergraduates in a Pakistani medical school. Medical Education. Vol.10, 2-10.

[8] K. F. Chung, M. M. Cheung. Sleep-wake patterns and sleep disturbance among Hong Kong chinese adolescents. SLEEP. Vol.31, No. 2, 185-193.

[9] C. Y. Sing, W. S. Wong. Prevalence of insomnia and its psychosocial correlates among college students in Hong Kong. Journal of American College Health. Vol.29, No.6, 174-82.

[10] S. M. Stewart, P. M. Lewinsohn, P. W. H. Lee, L. M. Ho, B. Kennard, C. W. Hughes, G. J. Emslie. Symptom patterns in depression and "subthreshold" depression among adolescents in Hong Kong and the United States. Journal of Cross-Cultural Psychology. Vol.33, No.6, 559-576.

[11] A-H. El-Gilany, M. Amr, S. Hammad. Perceived stress among male medical students in Egypt and Saudi Arabia: effect of sociodemographic factors. Annual Saudi Medicine. Vol.28, No.6, 442-448.

[12] R. T. Mikolajczyk, A. E. Maxwell, V. Naydenova, S. Meier, W. E. Ansari. Depressive symptoms and perceived burdens related to being a student: survey in three European countries. Clinical Practice and Epidemiology in Mental Health. Vol.4, 19-27.

[13] T. A. Brown, B. F. Chorpita, W. Korotitsh, D. H. Barlow. Psychometric properties of the Depression Anxiety Stress Scales (DASS) in clinical samples. Behavioral Research and Therapy. Vol.35, No.1, 79-89

[14] C. T. Streeramareddy, P. R. Shankar, V. S. Binu, C. Mukhopadhyay, B. Ray, R. G. Menezes. Psychological morbidity, sources of stress and coping strategies among undergraduate medical students of Nepal. BMC Medical Education. Vol.7, 26-33.

[15] P. C. Chou, Y. M. Y. Chao, H. J. Yang, G. L. Yeh, T. S. H. Lee. Relationships between stress, coping and depressive symptoms among overseas university preparatory Chinese students: a cross-sectional study. BMC Public Health. Vol.11, 352-359.

[16] C. S. M. Ng, J. Hurry. Depression amongst Chinese Adolescents in Hong Kong: an evaluation of a stress moderation model. Social Indicators Research. Vol.100, No.3, 499-516.

[17] M. Steinhardt, C. Dolbier. Evaluation of a resilience intervention to enhance coping strategies and protective factors and decrease symptomatology. Journal of American College Health. Vol.56, No.4, 445-453.

[18] H. B. Kaplan. Toward an understanding of resilience: A critical review of definitions and model. In, M. D. Glantz\& J. L. Johnson (Eds.), Resilience \& development: Positive life adaptations (pp. 17-83). New York: Kluwer Academic. 1999. United State.

[19] E. E. Taylor, J. D. Brown. Illusion and well-being: a social psychological perspective on mental health. Psychological Bulletin. Vol.103, 193-210.

[20] B. Major, C. Richards, M. L. Cooper, C. Cozzarelli, Zubek, J. Personal resilience, cognitive appraisals, and coping: an integrative model of adjustment to abortion. Journal of Personality and Social Psychology. Vol.74, 735-752.

[21] C. R. Wanberg. Antecedents and outcomes of coping behaviors among unemployed and reemployed individuals. Journal of Applied Psychology. Vol.82, 731-744.

[22] F. Y. Tung, J. C. Y. Wu, A. J. Hui, T. S. F. Chan. Psychiatric morbidity and quality of life of outpatients with irritable bowel syndrome. Hong Kong Journal of Psychiatry. Vol.19, 65-71.

[23] S. E. Ross, B. C. Niebline, T. M. Heckert. Sources of stress among college students. College Student Journal. Vol.33, No.2, 312-317.

[24] G. W. S. Wong, P. T. Cheung, K. K. C. Chan, K. K. Ma, S. W. Tung. Web-based survey of depression, anxiety and stress in first-year tertiary education students in Hong Kong. The Royal Australian and New Zealand College of Psychiatrists. Vol.40, 777-782.

[25] F. Ng, T. Trauer, S. Dodd, T. Callaly, S. Campbell, M. Berk. The validity of the 21-item version of the depression anxiety stress scales as a routine clinical outcome measure. ActaNeuropsychiatrica. Vol. 19, 304-310

[26] T. Torsheim, B. Wold. School related stress, school support and somatic complaints: a general population study. Journal of Adolescent Research. Vol. 16, 293-302.

[27] J. W. S. Chan, J. C. L. Lai, K. W. H. Wong. Resilience is associated with better recovery in Chinese people diagnosed with coronary heart disease. Psychology \& Health. Vol.21, No.3, 335-349.

[28] C. Lo, S. Cheung. Missing students' body found in Sai Kung reservoir. South China Morning Post. Retrieved from http://www.scmp.com/.

[29] S. Cohen, G. M. Williamson. Perceived stress in a probability sample of the United State. In: S. Spacapam, S. Oskamp. The social psychology of health: Claremont Symposium on applied social psychology. Newbury Park, CA, Sage. 1988. United State.

[30] S. Saxena, K. Chandiramani, R. Bhargava. WHOQOL Hindi: a questionnaire for assessing quality of life in health care setting in India. National Medicine Journal of India, Vol.11,160-166.

[31] WHOQOL Group. Development of the World Health Organization WHOQOL-Bref Quality of Life Assessment. Psychological Medicine. Vol.28, 551-558.

[32] J. D. Henry, J. R. Crawford. The short-form version of the Depression Anxiety Stress Scles (DASS-21): construct validity and normative data in a large non-clinical sample. Vol.44, 227-239.

[33] Y. W. Goh. The aetiology of occupational stress and coping. Doctoral dissertation, University of Queensland, Brisbane. Australia. 
[34] L. I. Pearlin, E. G. Menaghan, M. A. Lieberman, J. T. Mullan. The stress process. Jouranl of Health and Social Behavior, Vol.22, 337-356.

[35] D. T. L. Shek. Chinese culture beliefs about adversity: its relationship to psychological well-being, school adjustment and problem behavior in Chinese adolescents with and without economic disadvantage . Childhood. Vol.11, 63-80.

[36] D. T. L. Shek. A longitudinal study of Chinese cultural beliefs about adversity, psychological well-being, dislinquency, substance abuse in Chinese adolescents with economic disadvantages. Social Indicators Research. Vol.71, 358-409.

[37] D. T. L. Shek. Assessment of perceived parental psychological control in Chinese adolescents in Hong Kong. Research on Social Work Practice. Vol.16, 382-391.

[38] J. C. L. Lai, H. Cheung, W. H. Lee, H. Yu. The utility of the revised life orientation test to measure optimism among Hong Kong Chinese. International Journal of Psychology. Vol.33, No.1, 45-46.

[39] S. Frassrand. A comparative analysis of stress levels in undergraduate university students (Honors Thesis). University of Tennessee, Chattanooga, USA.

[40] M. Amponsah, H. O. Owolabi. Perceived stress levels of fresh university students in Ghana: a case study. British Journal of Education Research. Vol.1, No.2, 153-169.

[41] S. B. S. Khalsa, L. Hickey-Schultz, D. Cohen, N. Steiner, S.
Cope. Evaluation of the mental health benefit of yoga in a secondary school: a preliminary randomized controlled trial. The Journal of Behavioral Health Services \& Research. Vol.39, No.1, 80-89.

[42] J. J. Noggle, N. J. Steiner, T. Minami, S. B. S. Khalsa. Benefits of yoga for psychosocial well-being in a US high school curriculum: a preliminary randomized controlled trial. Journal of Developmental \& Behavioral Pediatrics. Vol.33, No.3, 193-201.

[43] E. Warnecke, S. Quinn, K. Ogden, N. Towle, M. R. Nelson. A randomized controlled trial of the effects of mindfulness practice on medical student stress levels. Medical Education. Vol.45, 381-388

[44] P. Ratanasiripong, N. Ratanasiripong, D. Kathalae. Biofeedback intervention for stress and anxiety among nursing students: a randomized controlled trial. International Scholarly Research Network. Vol.2012, 1-5.

[45] S. Stewart-Brown, J. Evans, J. Patterson, S. Petersen, H. Doll, J. Balding, D. Regis. The health of students in institutes of higher education: an important and neglected public health problem? Journal of Public Health Medicine. Vol.22, 492-299.

[46] C. C. Chen. An investigation into the relationship between the type and availability of recreational sport facilities and student lifestyle and social interaction in the United State Universities. Journal of Management and Humanity Science. Vol.1, No.2, 220-235. 